\title{
Evaluation of serum resistin levels in periodontal health and disease and effects of non surgical periodontal therapy on its levels
}

\author{
Archana Devanoorkar ${ }^{\mathrm{a}, *}$, C.D. Dwarakanath ${ }^{\mathrm{a}}$, Gayatri Gundanavar ${ }^{\mathrm{a}}$, Rahul Kathariya ${ }^{\mathrm{b}}$ and \\ Sudhir R Patil ${ }^{\mathrm{C}}$ \\ ${ }^{a}$ Department of Periodontics and Oral Implantology, Oxford Dental College Hospital and Research Centre, \\ Bangalore, India \\ ${ }^{\mathrm{b}}$ Department of Periodontology and Oral Implantology, Dr. D.Y. Patil Dental College and Hospital, Pune, India \\ ${ }^{\mathrm{c}}$ Department of Periodontics, KLE'S Institute of Dental Sciences and Research Center, Bangalore, India
}

\begin{abstract}
Background: Resistin and adiponectin are the adipokines secreted by adipocytes and various inflammatory cells. These adipokines are known to play an important role in insulin resistance. The aim of this study was to determine the serum resistin levels in periodontal health and disease and also, to determine the effect of nonsurgical periodontal therapy on its levels.

Methods: A total of 40 patients (20 Males and 20 Females; age range 20-50 years) participated in the study. Subjects were categorized as healthy (group 1; Controls) and chronic periodontitis (group 2; Study) groups based on their periodontal status. Periodontal parameters (Plaque index (PI), Gingival index (GI), Bleeding index (BI), Probing pocket depth (PPD), Clinical attachment loss (CAL)) together with serum resistin levels were assessed at baseline and between 6-8 weeks following nonsurgical periodontal therapy for subjects in group 2 and only at baseline in group 1. Sera were tested in duplicate (single run), and the results were averaged.

Results: Study group showed higher $(1.89 \pm 1.83 \mathrm{ng} / \mathrm{ml})$ serum resistin levels, compared to control group $(1.35 \pm 0.70 \mathrm{ng} / \mathrm{ml})$. However, this difference was not statistically significant $(P=0.227)$. Also, resistin levels decreased following nonsurgical periodontal therapy but, this decrease failed to show any statistical significance, with pretreatment levels being $1.89 \pm 1.83 \mathrm{ng} / \mathrm{ml}$ and post treatment levels being $1.59 \pm 1.01 \mathrm{ng} / \mathrm{ml}(P=0.386)$.

Conclusion: Observations of the present study revealed that there was not much difference in the serum resistin levels between the cases and the controls. Also the decrease in the resistin levels following nonsurgical periodontal therapy did not show any statistical significance.
\end{abstract}

Keywords: Biomarkers, adipocytes, resistin, serum, chronic periodontitis, insulin resistance

\section{Introduction}

Periodontitis is a common oral disease of multifactorial etiology wherein microbial pathogens play an important role. Plaque bacteria and its products such as endotoxins elicit the host immunoinflammatory re-

${ }^{*}$ Corresponding author: Dr. Archana Devanoorkar, Senior Lecturer, Department of Periodontics and Oral Implantology, AME'S Dental College, Raichur 584103, Karnataka, India. Tel.: +91 90369 22517/+91 93793 35197; E-mail: dr.archanashivm@gmail.com. sponse. This immunoinflammatory response against the microbes, in an attempt to wall off the infection results in the local tissue destruction by producing various proinflammatory mediators such as prostaglandin E2 (PGE2), tumor necrosis factor (TNF) $\alpha$ and interleukin (IL) 1, IL 6 etc. [1]. These proinflammatory mediators in addition to local tissue destruction also exert certain systemic effects [2]. A two way relationship has been established between diabetes and periodontitis wherein one can influence the other. Obesity which is another important risk factor for type 2 diabetes has also been 
linked to periodontitis [3]. Obesity is characterized by increase in the adipose tissue which is an important source for various proinflammatory cytokines such as TNF- $\alpha$, IL, visfatin, adiponectin and resistin [4]. Resistin and TNF- $\alpha$ are known to play an important role in inducing insulin resistance. Resistin is a cysteine rich protein found in the inflammatory zone. It derived its name from the original observation that it induces insulin resistance in mice (Resistin means 'to resist'), and it down regulates mature murine adipocytes when cultured in presence of insulin sensitizing drugs such as thiozolidinediones. Initially it was thought that resistin is mainly produced by the adipocytes. However recent studies have shown that large amount of resistin is produced from cells of the immunoinflammatory system like PMN's, monocytes and macrophages [4]. Resistin may be one of the markers that provides a connecting link between periodontitis-obesity-diabetes mellitus triad. Hence this study was intended to determine the levels of resitin in periodontal health and disease and also to determine the effect of nonsurgical periodontal therapy on its levels.

\section{Materials and methodology}

\subsection{Subject selection}

This study was carried out from September 2009 to August 2010. The study population consisted of 40 age and gender balanced (20 males, 20 females, age range: 20-50 years) systemically healthy subjects, attending the Outpatient Section, Department of Periodontics, Oxford Dental College, Hospital and Research Centre, Bangalore, India. Written informed consent was obtained from those who agreed to participate voluntarily. Ethical clearances were obtained from the institution's ethical committee and review boards.

Subjects having a minimum of 20 teeth present were randomly selected and categorized into study and control groups. Subjects who were on medications and those with known systemic diseases that might affect the course of periodontal disease, a history of smoking or use of tobacco in any forms, subjects with BMI $>25 / \mathrm{m}^{2}$, pregnant and lactating women, and those with periodontal treatment within past 6 months, and those unwilling to participate in the study were excluded. All the subjects included in the study had oral hygiene habit of brushing only once a day and did not use any other oral hygiene aids other than brushing. Subjects satisfying the above mentioned criteria's were included and categorized into 2 groups of 20 each, as healthy (Group 1: Subjects with no history of periodontal disease, with probing depths of $\leqslant 3 \mathrm{~mm}$ and clinical attachment (CAL) of $\leqslant 1 \mathrm{~mm}$ with full mouth bleeding scores (Ainamo et al. 1975) less than 10\%.) and chronic periodontitis (Group 2: Subjects having $\geqslant$ $5 \mathrm{~mm}$ pocket or attachment loss of $\geqslant 2 \mathrm{~mm}$ in at least 4 teeth with radiographic evidence of bone loss) [5,6].

A previously calibrated examiner (AD) performed all the clinical assessments using a University of North Carolina (UNC)-15 periodontal probe,${ }^{1}$ to ensure adequate intra-examiner reproducibility. The following clinical parameters were assessed for the subjects in both the groups i.e. Plaque Index [7] (PI), Gingival Index [8] (GI), Bleeding Index [9] (BI), Probing Pocket Depth (PPD), Clinical attachment level (CAL). The PPD and CAL values were estimated to their nearest millimeter.BMI was calculated for each subject enrolled in the study using $(\mathrm{kg}) / \mathrm{ht}\left(\mathrm{m}^{2}\right)$. Subjects with BMI $>25 \mathrm{~kg} / \mathrm{m} 2$ were excluded.

\subsection{Collection of blood samples}

Using a 20-guage needle with $2 \mathrm{ml}$ syringes, about $2 \mathrm{ml}$ of blood was collected from the antecubital fossa by venipuncture into a serum separator tube. Collected samples were immediately transferred to the laboratory, where samples were allowed to clot for 30 minutes before centrifugation for 15 minutes at $1000 \times g$. serum was separated for analysis and immediately transferred to a plastic vial and stored at $-20^{\circ} \mathrm{C}$. Care was taken to avoid repeated thaw cycles.

\subsection{Clinical procedure}

On the first visit, a detailed case history including clinical parameters, and venous blood samples for investigations were collected for all the subjects, and for subjects of chronic periodontitis (group 2) blood samples were recollected between 6-8 weeks after nonsurgical periodontal therapy. All the samples were assessed for fasting blood sugar level and leukocyte count. After all the data was collected, comprehensive phase I therapy was given to the subjects in group II. Following this the patient's returned once in two weeks for maintenance of oral hygiene. Estimation of serum resistin levels was done by using 'Human Resistin Assay Immunoassay obtained' from 'Research and Development Systems $^{2}$ TM USA'.

\footnotetext{
${ }^{1}$ UNC-15,Hu-Friedy, Inc. Chicago, Illinois (IL), USA.

${ }^{2} \mathrm{R} \& \mathrm{D}$ systems, Inc.TM Minneapolis (MN), USA.
} 
Table 1

BMI distribution

\begin{tabular}{crrrrr}
\hline BMI $\left(\mathrm{kg} / \mathrm{m}^{2}\right)$ & \multicolumn{2}{c}{ Controls } & & \multicolumn{2}{c}{ Cases } \\
\cline { 2 - 3 } \cline { 5 - 6 } & No & $\%$ & & No & $\%$ \\
\hline$<18.0$ & 2 & 10.0 & & 0 & 0.0 \\
$18.0-23.0$ & 18 & 90.0 & & 19 & 95.0 \\
$>23.0$ & 0 & 0.0 & & 1 & 5.0 \\
Total & 20 & 100.0 & & 20 & 100.0 \\
\hline Mean $\pm \mathrm{SD}$ & $19.38 \pm 1.78$ & & $20.80 \pm 1.60$ \\
\hline
\end{tabular}

\subsection{Assay procedure}

This assay employed the quantitative sandwich enzyme immunoassay technique. Amount of resistin was measured by intensity of the colour produced, at wavelength of $450 \mathrm{~nm}$. All the steps were carried out according to manufacturer's instructions to determine the serum resistin levels in the samples collected. Samples were duplicated (single run) and the results were averaged for better evaluation. All the recorded data were subjected for statistical evaluation.

\subsection{Statistical methods}

All data were analyzed using a software program. ${ }^{3}$ Descriptive statistical analysis has been carried out in the present study. Results on continuous measurements are presented as Mean \pm SD and results on categorical measurements are presented in Number (\%). Significance is assessed at $5 \%$ level of significance. Student $\mathrm{T}$ test (two tailed, independent), for Bleeding Index, Mann -Whitney U test for inter-group analysis and Wilcoxon signed rank test for within each group was done. Chi-square/ Fisher Exact test has been used to find the significance of study parameters.

\section{Results}

The age of the participants ranged between 20 and 50 years. The BMI of the subjects ranged from 1724. The mean BMI of the subjects in group 1 and 2 were $19.38 \pm 1.78 \mathrm{~kg} / \mathrm{m}^{2}$ and $20.80 \pm 1.60 \mathrm{~kg} / \mathrm{m}^{2}$ respectively (Table 1).

\subsection{Serum resistin levels}

It was found that serum resistin level was slightly greater in group 2 as compared to group 1 . However this difference was not statistically significant with $(P=$

\footnotetext{
${ }^{3}$ Software Analyzer- SPSS 17.1 SPSS Inc., Chicago, IL, USA.
}

Table 2

Comparison of serum resistin levels between two groups

\begin{tabular}{clc}
\hline Serum resistin $(\mathrm{ng} / \mathrm{dl})$ & Controls & Cases \\
\hline Min-Max & $0.33-3.01$ & $0.17-7.97$ \\
Mean $\pm \mathrm{Sd}$ & $1.35 \pm 0.70$ & $1.89 \pm 1.83$ \\
\hline Inference & Serum resistin level is slightly elevated \\
& in cases but not statistically significant \\
& with $P=0.227$ & \\
\hline
\end{tabular}

0.227) (Table 2). Non surgical periodontal therapy had a small effect on serum resistin levels with the baseline value being $1.89 \pm 1.83 \mathrm{ng} / \mathrm{ml}$ and the post treatment value being $1.59 \pm 1.01 \mathrm{ng} / \mathrm{ml}$. This was found to be statistically insignificant $(P=0.386)$ (Table 4$)$.

\subsection{Total leukocyte count}

Total leukocyte count at base line between the two groups was statistically insignificant $(P=0.250)$ (Table 3). After non surgical periodontal therapy though there was decrease in the total leukocyte count it did not reach any statistical significance $(P=0.558)$ (Table 4$)$.

\subsection{Fasting blood sugar level}

At baseline the FBS levels in group 1 and 2 were $86.60 \pm 9.84 \mathrm{mg} / \mathrm{dl}$ and $96.65 \pm 9.94 \mathrm{mg} / \mathrm{dl} \mathrm{respec}-$ tively (Table 3$)$. A strongly significant difference $(P<$ 0.003 ) was found in the FBS level between Group 1 and 2. Non surgical periodontal therapy had a large effect on FBS level with pre treatment levels being $96.65 \pm$ $9.94 \mathrm{mg} / \mathrm{dl}$ and post treatment levels being $88.70 \pm$ $9.38 \mathrm{mg} / \mathrm{dl}$ this was found to have high statistically significance $(P<0.004)$ (Table 4$)$.

\subsection{Periodontal status}

Statistically significant difference was found for Plaque index (PI), Gingival Index (GI), Bleeding in$\operatorname{dex}(\mathrm{BI})$, Probing pocket depth (PPD), between the two groups (Table 5) and there was a statistically significant improvement in all the clinical periodontal parameters following nonsurgical periodontal therapy for subjects in group 2 (Table 6).

Pearson's correlation coefficient: There was a positive correlation between the serum resistin levels and PI, GI, BI, PPD, Fasting Blood sugar (FBS), and Total count (TC), however it had negative correlation with Clinical attachment levels (CAL) (Table 7). 
Table 3

Comparison of total leukocyte count and fasting blood glucose between two groups

\begin{tabular}{|c|c|c|c|}
\hline Biochemical parameters & Controls & Cases & $P$ value \\
\hline Total leukocyte counts (cells $/ \mathrm{mm}^{3}$ ) & $8310.00 \pm 2261.56$ & $8995.00 \pm 1326.44$ & 0.250 \\
\hline FBS $(\mathrm{mg} / \mathrm{dl})$ & $86.60 \pm 9.84$ & $96.65 \pm 9.94$ & $0.003^{* *}$ \\
\hline
\end{tabular}

** Statistical significance levels $P<0.05$.

Table 4

Effect of treatment on serum resistin, total count and FBS

\begin{tabular}{lccccc}
\hline & Before & After & P value & delta & Effect size \\
\hline Serum resistin $(\mathrm{ng} / \mathrm{dl})$ & $1.89 \pm 1.83$ & $1.59 \pm 1.01$ & 0.386 & 0.29 & $0.21(\mathrm{~S})$ \\
Total leukocyte count $\left(\right.$ cells $\left./ \mathrm{mm}^{3}\right)$ & $8995.00 \pm 1326.44$ & $8685.00 \pm 2579.53$ & 0.558 & 310.0 & $0.23(\mathrm{~S})$ \\
FBS $(\mathrm{mg} / \mathrm{dl})$ & $96.65 \pm 9.94$ & $88.70 \pm 9.38$ & $0.004^{* *}$ & 7.95 & $0.82(\mathrm{~L})$ \\
\hline
\end{tabular}

${ }^{* *}$ Statistical significance levels $P<0.05$.

Table 5

Comparison of clinical variables between two groups

\begin{tabular}{lrrc}
\hline Clinical variables & \multicolumn{1}{c}{ Controls } & \multicolumn{1}{c}{ Cases } & P value \\
\hline Plaque Index & $0.08 \pm 0.21$ & $1.76 \pm 0.29$ & $<0.001^{* *}$ \\
Gingival Index & $0.0755 \pm 0.22$ & $1.85 \pm 0.25$ & $<0.001^{* *}$ \\
Bleeding Index & $3.17 \pm 2.43$ & $94.91 \pm 9.80$ & $<0.001^{* *}$ \\
Probing depth & $1.75 \pm 0.38$ & $3.49 \pm 0.61$ & $<0.001^{* *}$ \\
\hline
\end{tabular}

** Statistical significance levels $P<0.05$.

Table 6

Effect of treatment on clinical variables in cases

\begin{tabular}{lccccc}
\hline Clinical variables & \multicolumn{1}{c}{ Before } & \multicolumn{1}{c}{ After } & P value & delta & Effect size \\
\hline Plaque Index & $1.76 \pm 0.29$ & $0.73 \pm 0.46$ & $<0.001^{* *}$ & 1.03 & $2.75(\mathrm{VL})$ \\
Gingival Index & $1.85 \pm 0.25$ & $0.92 \pm 0.37$ & $<0.001^{* *}$ & 0.93 & $3.00(\mathrm{VL})$ \\
Bleeding Index & $94.91 \pm 9.80$ & $36.12 \pm 21.91$ & $<0.001^{* *}$ & 58.78 & $3.70(\mathrm{VL})$ \\
Probing depth & $3.49 \pm 0.61$ & $2.96 \pm 0.63$ & $<0.001^{* *}$ & 0.53 & $0.85(\mathrm{~L})$ \\
CAL & $5.33 \pm 0.54$ & $4.69 \pm 0.62$ & $<0.001^{* *}$ & 0.64 & $1.10(\mathrm{~L})$ \\
\hline
\end{tabular}

** Statistical significance levels $P<0.05$.

Table 7

Pearson correlation of serum resistin levels with clinical variables, total leukocyte counts and FBS levels in cases

\begin{tabular}{ccc}
\hline Serum resistin V/s & Pearson correlation & P value \\
\hline PI & 0.229 & 0.331 \\
GI & 0.232 & 0.325 \\
BI & 0.258 & 0.272 \\
PD & 0.178 & 0.452 \\
CAL & -0.026 & 0.916 \\
TC & 0.092 & 0.701 \\
FBS & 0.094 & 0.694 \\
\hline
\end{tabular}

\section{Discussion}

Various pro inflammatory cytokines have been studied that have shown to play an important role in the periodontal pathogenesis, one such newly recognized group of cytokines are adipokines. Adipokines such as adiponectin and resistin are postulated to act through their effects on insulin sensitivity and recent evidence suggests an important role of these adipokines in the inflammatory process [10].
Results of the present study showed that there is increased level of serum resistin in study group (1.89 \pm $1.83 \mathrm{ng} / \mathrm{ml}$ ) as compared to control group (1.35 \pm $0.70 \mathrm{ng} / \mathrm{ml}$ ). However this difference was not statistically significant. Findings of this study are in agreement with the results of a previous study by Furugen et al., wherein it was observed that there was increased resistin levels and decreased adiponectin levels in patients with periodontitis which were also not significant [2]. In another study [11] estimation of resistin levels in serum and synovial fluid of patients with rheumatoid arthritis showed that the serum levels of resistin in patients with rheumatoid arthritis did not differ than their healthy counter parts. However there was highly significant correlation between resistin levels and the synovial fluid correlating with localized accumulation of WBC's indicating that resistin exerted an local inflammatory reaction [11]. In addition it is also observed that there was no significant difference in the serum resistin levels in healthy and subjects with stable angi- 
na, however there was significantly increased resistin levels in patients with unstable angina indicating that resistin levels in the serum are mainly related to severity of inflammation rather than a mere association with inflammatory process [12].

In the present study the serum resistin levels were positively correlated with the periodontal parameters such as PI, GI, BI, and PD except for CAL with which it had a negative correlation. However these correlations were not statistically significant. This indicates that the resistin levels may be associated with inflammatory variables rather than the periodontal destruction as indicated by negative correlation with CAL. This finding is in agreement with the Furugen et al. study where in they also did not find any significant correlation between resistin and CAL [2].

In this study the total leukocyte count was slightly greater in the study group as compared with the control group although, the difference was not statistically significant. This finding is in agreement with the results of previous study [12].

Additional finding of our study was that there was statistically significant difference in the FBS levels between the control and study group. FBS had a positive correlation with serum resistin levels. These findings are in agreement with the findings of previous study [13]. There was a significant reduction in FBS following SRP. These findings are comparable to the findings of previous study where in periodontal therapy improved the insulin sensitivity resulting in the improvement of glycemic control as predicted by glycated hemoglobin levels, however these studies were done in diabetics but the present study excluded the known diabetics $[14,15]$.

In the present study, we found that BMI has a suggestive significance on the serum resistin levels. Observations of this study are in agreement with the findings of previous studies $[16,17]$. Although there was a decrease in the serum resistin levels following nonsurgical periodontal therapy, this difference did not reach any statistical significance. This indicates that periodontal therapy (SRP) was less effective in decreasing the serum resistin levels. Findings of the this study are in agreement with the observations of previous study wherein nonsurgical periodontal therapy in the form of SRP was not effective in altering (increasing) the serum adiponectin levels in patients with chronic periodontitis $[18,19]$.

Thus, it could be inferred from the above findings that adiponectin and resistin both being adipokines may respond similarly to periodontal therapy. To the best of our knowledge there are no previous studies to determine the effects of nonsurgical periodontal therapy on serum resistin levels. Drawing parallels with other inflammatory conditions of the body it can be inferred here also that the level of inflammation should be severe in order to notice significant changes in serum resistin levels. Although there was significant improvement in the clinical parameters following nonsurgical periodontal therapy, the same was not reflected in the serum resistin levels. Hence it is obvious that other factors including the genetic predisposition of the individuals may also have a role in the regulation of resistin levels.

Increased level of serum resistin in certain chronic inflammatory diseases is mainly associated with the severity of diseases rather than its mere presence [12]. This reveals that the resistin plays a role in the inflammatory process, but the exact molecular mechanism of action has not yet been completely understood to give a direct cause and effect relationship between serum resistin levels and various chronic inflammatory diseases and so in periodontitis.

Based on the findings of the present study, it could be concluded that serum resistin is influenced by many other factors in addition to periodontal inflammation and it would be difficult to consider it as a marker for periodontitis that could link the periodontitis with other systemic conditions such as type 2 diabetes, Cardio Vascular Diseases (CVD) etc. Further long term interventional studies with larger sample size may give a more clear relationship between the serum resistin periodontitis and its use as one of the marker for periodontal destruction and also to link resistin with the systemic conditions that are influenced by periodontitis and to claim its usefulness as a marker for periodontitis.

\section{Acknowledgement}

The authors acknowledge Mr. Suresh KP, (Scientist, Statistician, National Institute of Animal Nutrition \& Physiology (NIANP), Bangalore, India) for helping us prepare the statistics of the study, and Dr. Karuna, (Prof. and Head, Department of Pathology, St John's Medical College and Hospital Bangalore) for helping us running the ELISA.

\section{Conflict of interest}

1. The authors report no conflict of interests.

2. It is a self funded research. 


\section{References}

[1] Graves DT and Cochran D, The contribution of interleukin-1 and tumor necrosis factor to periodontal tissue destruction. $J$ Periodontol 2003; 74: 391-401.

[2] Furugen R, Hayashida H, Yamaguchi N, Yoshihara A, Ogawa $\mathrm{H}$, Miyazaki $\mathrm{H}$ and Saito $\mathrm{T}$. The relationship between periodontal condition and serum level of resistin and adiponectin in elderly Japnese. J Periodont Res 2008; 43: 556-562.

[3] Nishimura F, Yohihiro I, Junji M, Akemi S, Yoshihiko S and Murayama Y. Periodontal disease and diabetes mellitus: The role of tumor necrosis factor- $\alpha$ in a 2-way relationship. $J$ Periodontol 2003; 74(1): 97-102.

[4] Pischon N, Heng N, Bernimoulin JP, Kleber BM, Willich SN and Pischon T. Obesity, inflammation and periodontal disease. J Dent Res 2009; 86(5): 400-409

[5] American Academy of Periodontology. Parameter on chronic periodontitis with slight to moderate loss of periodontal support. J Periodontol 2000; 71(S5): 853-855.

[6] American Academy of Periodontology. Parameter on chronic periodontitis with advanced loss of periodontal support. J Periodontol 2000; 71(S5): 856-858.

[7] Silness $\mathrm{P}$ and Loe H. Periodontal disease in pregnancy. Correlation between oral hygiene and periodontal conditions. Acta Odontol Scand 1964; 22: 121-135.

[8] Loe $\mathrm{H}$ and Silness J. Periodontal disease in pregnancy. I Prevalence and severity. Acta Odontol Scand 1963; 21: 533-551.

[9] Ainamo J and Bay I. Problems and proposals for recording gingivitis and plaque. Int Dent Journal 1975; 25:229-235.

[10] Pang S and Le Y. Role of resistin in inflammation and inflammation related diseases. Cellular and molecular Immunol 2006; 3(1): 29-34.

[11] Bokarewa M, Nagaev I, Dahlberg L, Smith U and Tarkowski A. Resistin, an adipokine with potent proinflammatory properties. J Immunol 2005; 174: 5789-5795.

[12] HU Wen-lan, QIAO Shu-bin, HOU Qing and YUAN Jiansong. Plasma resistin is increased in patients with unstable angina. Chin Med J 2007; 120(10): 871-875.
[13] Bo S, Gambino R, Pagani A, Guidi S, Gentile L, Cassader M, Pagano GF. Relationships between human serum resistin, inflammatory markers and insulin resistance. Int J obes 2005; 29: $1315-1320$

[14] Grossi SG, Skrepcinski FB, De Caro T, Robertson DC, Ho AW, Dunford RG, Genco RJ. Treatment of periodontal disease in diabetics reduces glycated hemoglobin. J Periodontol 1997; 68: 713-719.

[15] Iwamoto Y, Nishimura F, Nakagawa M, Sugimoto H, Shikata $\mathrm{K}$ and $\mathrm{H}$ Makino, Fukuda T, Tsuji T, Iwamoto M, Murayama Y. The effect of antimicrobial periodontal treatment on circulating tumor necrosis factor-alpha and glycated hemoglobin level in patients with type 2 diabetes. J Periodontol 2001; 72(6): 774-778.

[16] Yanakoula M, Yannakouris N, Bluher S, Leda Matalas A, Klimis-Zacas D, Mantzoros CS. Body fat mass and macronutrient intake in relation to circulating soluble leptin receptor, free leptin index, adiponectin, and resistin concentrations in healthy humans. J Clin Endo Metab 2003; 88(4): 1730-1736.

[17] Mahaweerawat U, Somdee T, Sungkamanee S, Yangyuen S and Pichainarong $\mathrm{N}$. The relationship of serum resistin concentration and body mass index (BMI) of obese adolescent in mahasarakam province. J Sci Technol MSU 2008; 27(4): 362-368.

[18] Iwamoto Y, Nishimurga F, Soga Y, Takeuchi K, Kurihara M, Takashiba S, Murayama Y. Antimicrobial periodontal treatment decreases serum C-reactive protein, tumor necrosis factor- alpha, but not adiponectin levels in patients with chronic periodontitis. J Periodontol 2003; 74(8): 1231-1236.

[19] Matsumoto S, Ogawa H, Soda S, Hirayama S, Amarasena N, Aizawa Y, Miyazaki H. Effect of antimicrobial periodontal treatment and maintenance on serum adiponectin in type II diabetes mellitus. J Clin Periodontol 2009; 36(2): 142-148.

[20] Haber J, Wattles J, Crowely M, Mandell R, Joshipura K, Kent RL. Evidence for cigarette smoking as a major smoking as a major risk factor for periodontitis. J Periodontol 1993; 64: $16-23$. 


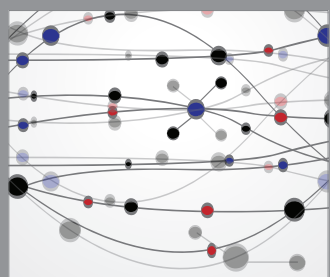

The Scientific World Journal
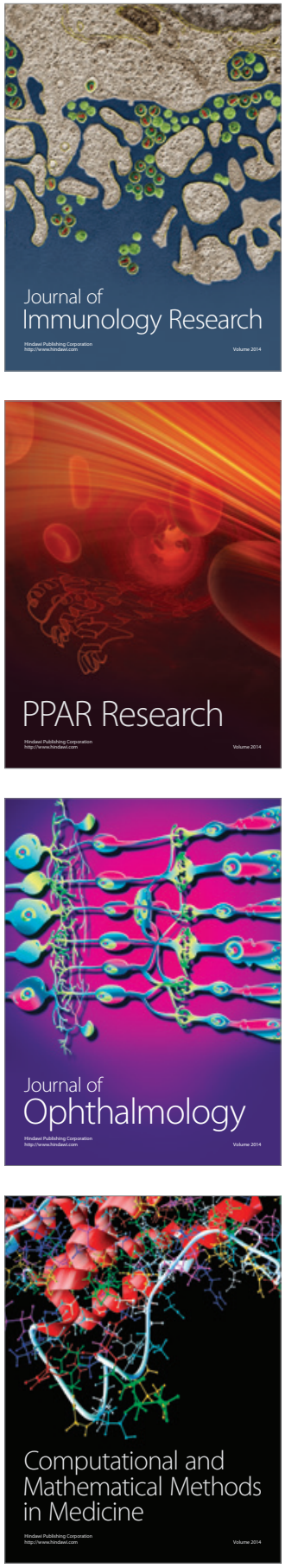

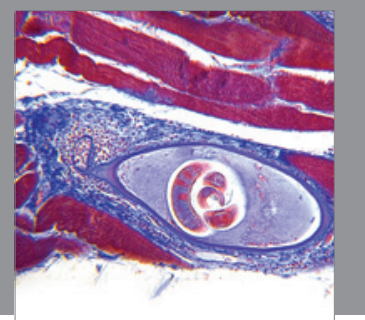

Gastroenterology

Research and Practice
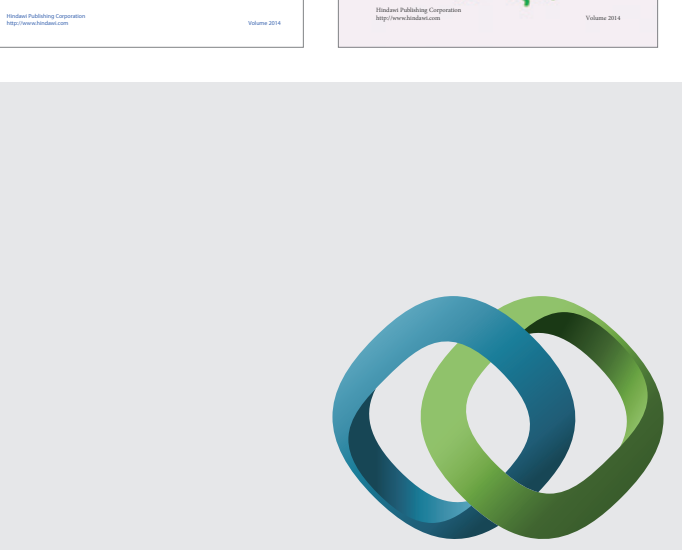

\section{Hindawi}

Submit your manuscripts at

http://www.hindawi.com
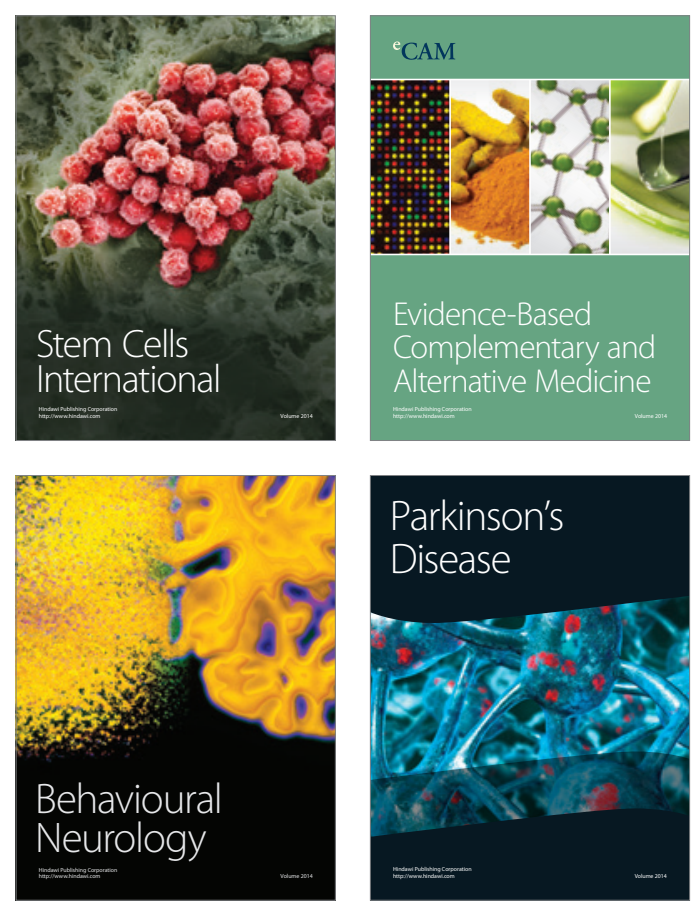

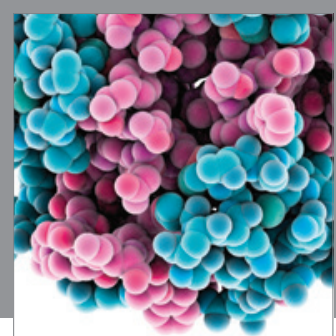

Journal of
Diabetes Research

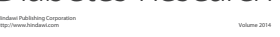

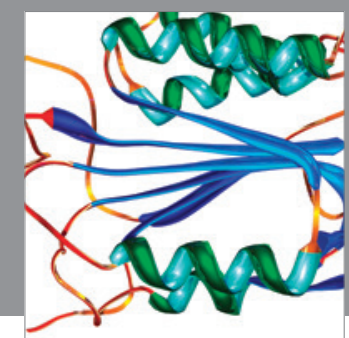

Disease Markers
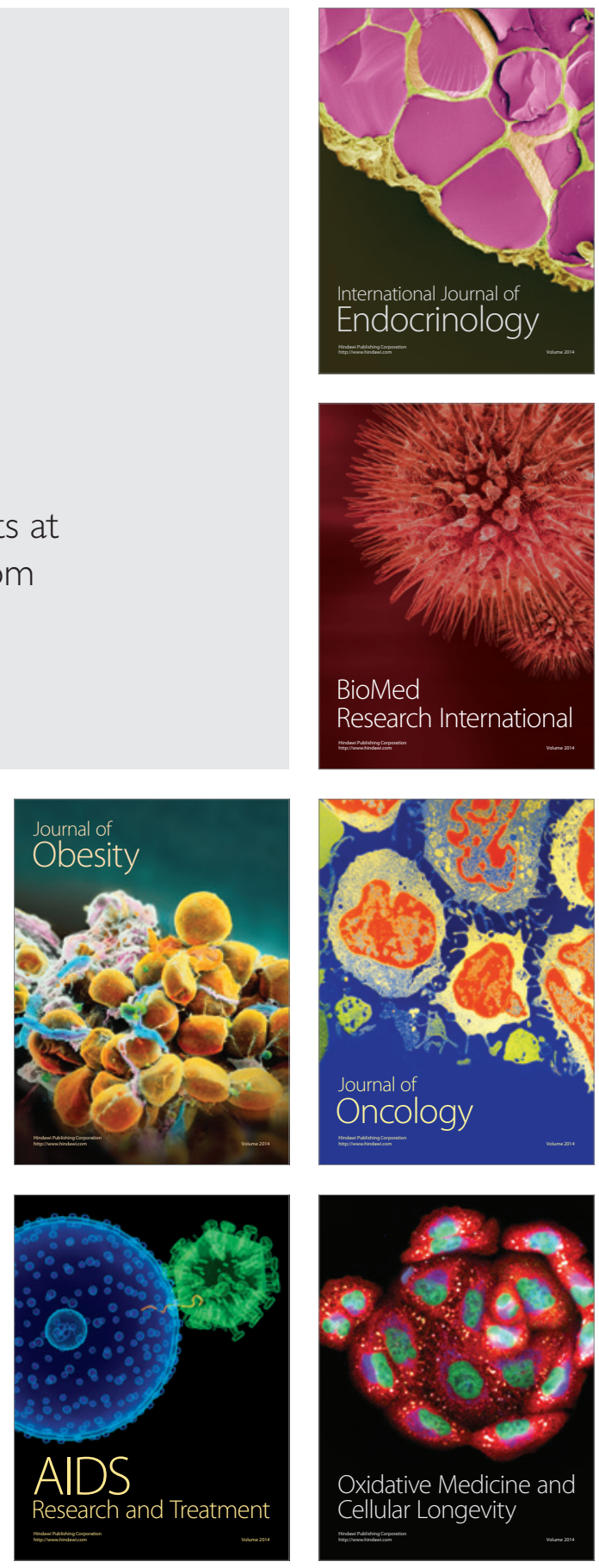